\title{
Nanowastes riscos para saúde humana e meio ambiente: diálogos entre o princípio da precaução e a sociedade de risco
}

\author{
Nanowastes risks to human health and \\ the environment: dialogue between the \\ precautionary principle and risk society
}

\author{
Liziane Paixão Silva Oliveira ${ }^{1}$ \\ Universidade Tiradentes (Brasil)
}

Maria Edelvacy Marinho ${ }^{2}$

Centro Universitário de Brasília (Brasil)

Ellen de Oliveira Fumagali ${ }^{3}$

Universidade Tiradentes (Brasil)

Recibido: 27-11-14

Aprobado: 15-01-15

\section{Resumo}

A nanotecnologia é um dos ramos da ciência que mais se desenvolveu nas últimas décadas, com aplicações em diversas áreas estratégicas: saúde, energia, eletrônicos, vestuário, meio ambiente, entre outras. O aumento da produção

\footnotetext{
${ }^{1}$ (lizianepaixao@gmail.com). Doutora em Direito Internacional pela Université d'Aix-Marseille III, Mestre em Direito pela UNB, Coordenadora do Programa de Pós-Graduação em Direito da UNIT, Líder do Grupo de Pesquisa vinculado ao CNPq Novas tecnologias e o impacto nos Direitos Humanos. Publicações: Oliveira, Liziane Paixão Silva: La protection de l'environnement dans le traité d'Asunción: un engagement 'soft', "Revista Jurídica da Presidência", v. 16, p. 321-344, 2014; Oliveira, Liziane Paixão Silva: Clause d'exception environnementale et le Mercosur, "Nomos" (Fortaleza), v. 33.1, p. 421-444, 2013; Alves, G. R.; Oliveira, Liziane Paixão Silva: A jurisdicização do órgão de solução de controvérsias da OMC e a promoção do desenvolvimento sustentável, "Hegemonia" (Brasília), v. 11, p. 36-68, 2013.

2 (mariaedelvacy@gmail.com). Doutora em Direito pela Universidade Paris 1- Panthéon Sorbonne. Professora do Programa de Mestrado e Doutorado do Uniceub. Consultora. Publicações: Marinho, Maria Edelvacy Pinto; Silva, S. T.: Diálogos entre juízes: condições e critérios para a identificação do fenômeno diálogo entre juizes. In: Maria Edelvacy Marinho; Solange Teles da Silva; Liziane Paixão Silva Oliveira. (Org.): Dialogo entre juizes. 1ed.Brasilia: Uniceub, 2014, p. 27-38; Varella, M. D.; Marinho, Maria Edelvacy Pinto: Contesting Monsanto's Patents on Life: Transnational Juridical Dialogue and the Influence of the European Court of Justice on Soybeans Exporting Countries. "Tulane Journal of Technology and Intellectual Property, v. 16, p. 79-104, 2013; Marinho, Maria Edelvacy Pinto: Les processus d'internationalisation du droit des brevets. ÉDITIONS UNIVERSITAIRES EUROPÉENNE, 2010.

${ }^{3}$ (ellenfumagali@hotmail.com). Mestranda em Direitos Humanos pela Universidade Tiradentes. Advogada. Especialista em Direito Aplicado, pela Escola de Magistratura do Paraná, Brasil (2006). É membro em diretório de grupo de pesquisa vinculado ao CNPq: "Novas tecnologias e o impacto nos Direitos Humanos".
} 
e do consumo de nanoprodutos tem acarretado a ampliação da quantidade de nanowastes no meio ambiente. Contudo, pouco se tem discutido acerca dos impactos desses resíduos no ambiente, na saúde das pessoas, animais e vegetais. Em virtude das incertezas científicas que norteiam o assunto, recomenda-se a aplicação do princípio da precaução, como instrumento hábil a possibilitar o gerenciamento dos riscos produzidos pelas nanotecnologias. Por outro lado, procura-se avaliar os perigos ecológicos nos contornos da Sociedade de Risco, em relação aos preceitos estabelecidos por Ulrich Beck e Niklas Luhmann.

Palabras-chave: Nanotecnologia, Nanowastes, Princípio da Precaução, Sociedade de Risco

\section{Abstract}

Nanotechnology is a branch of science that has developed over the past decades, with applications in several key areas: health, energy, electronics, clothing, environment, among others. Increased production and consumption of nanoproducts has entailed expanding the amount of nanowastes in the environment. However, little has been discussed about the impacts of these wastes into the environment, the health of people, animals and plants. Because of the scientific uncertainties the application of the precautionary principle is a subtle instrument that allows the management of risks caused by nanotechnologies. On the other hand, seeks to assess the ecological dangers in the contours of the Risk Society, in relation to the precepts established by Ulrich Beck and Niklas Luhmann. Society

Key-words: Nanotechnology, Nanowastes, Precautionary Principle, Risk

\section{Introdução}

Estudos indicam a possibilidade de a produção global de nanomateriais atingir 58 mil toneladas entre os anos de 2011 a $2020^{4}$. Apesar do aumento expressivo do uso de nanomateriais, pouco tem se discutido sobre os riscos associados aos resíduos gerados na sua produção e descarte. Esse fato pode ser compreendido como mais um exemplo da sociedade de risco, identificada nos estudos de Niklas Luhmann e Ulrick Beck. A ciência que soluciona problemas também os produz. E o risco está associado à decisão que se toma diante das incertezas geradas pela introdução de novas de tecnologias. Do ponto de vista

4 A. D.Maynard, Nanotechnology: A Research strategy for addressing risk, Woodrow Wilson International Center for Scholars, 2006. 
jurídico, a ausência de provas inequívocas de que determinada tecnologia ou produto gera mais prejuízo do que benefícios à sociedade/meio ambiente dificulta a configuração do nexo causal entre o uso da tecnologia e suas consequências. $\mathrm{O}$ princípio da precaução atua exatamente nessa lacuna onde ainda não há certeza científica. O objetivo desse artigo é partir dos conceitos elaborados sobre a sociedade de risco para se analisar o tratamento conferido aos nanomateriais. Primeiramente serão abordadas algumas características da sociedade de risco, pertinentes ao tema, seguidas do conceito de nanotecnologia, da análise de custo e benefícios da nanotecnologia e, por fim, o tratamento jurídico dos nanowastes.

\section{Sociedade de risco e novas tecnologias}

Na era industrial, o desenvolvimento tecnológico representava uma solução aos problemas do homem relacionados à produtividade, saúde e escassez, enquanto na sociedade de risco, ele é solução e também problema ${ }^{5}$. A sociedade de risco se caracterizaria, na visão de Ulrich Beck, por uma reflexividade ${ }^{6}$ : o homem passa a sofrer as consequências de suas decisões e tais consequências não são, em sua grande maioria, restrita àqueles que os criaram. Os riscos, mesmo aqueles criados localmente, podem se propagar em escala global. E as decisões, para minimizar seus efeitos, necessitam da cooperação dos Estados, pois a solução não está restrita a fronteiras. Entre os atores relevantes na sociedade de risco, destacam-se os tomadores de decisão ${ }^{7}$. Eles selecionam os riscos que serão considerados como relevantes e desprezíveis. A classe política, os cientistas e a mídia atuam na definição do risco socialmente aceitável. Para Beck "a sociedade de Risco é, nesse sentido, também a sociedade da ciência, da mídia e da informação. Nela, escancaram-se, assim, novas oposições entre aqueles que produzem definições e aqueles que consomem".

A noção de risco, utilizada nesse artigo, está associada à incerteza científica presente durante a tomada de decisão. Apesar da percepção sobre o que seria considerado como risco e o grau de sua aceitabilidade variar conforme a sociedade é possível identificar alguns elementos comuns caracterizadores da definição de risco. O primeiro, como já dito, é a incerteza. A ciência não é capaz, em alguns casos, principalmente envolvendo novas tecnologias, de prever com elevado grau de certeza as possíveis consequências de sua utilização para a saúde humana e para o meio ambiente 9 . Para Luhmann a sociedade vê a ciência como uma fábrica

${ }^{5}$ UlrichBeck, Sociedade de Risco: rumo a uma outra modernidade, São Paulo, Editora 34, 2010.

${ }^{6}$ UlrichBeck, Sociedade de Risco: rumo a uma outra modernidade, São Paulo, Editora 34, 2010, pág. 24.

7 NiklasLuhmann, Risk: a sociology theory, New Jersey, Translation Publishers, 2008.

${ }^{8}$ UlrichBeck, Sociedade de risco: rumo a uma outra modernidade, São Paulo, Editora 34, 2010, pág. 56.

9 "As fontes de perigo já não são mas o desconhecimento, e sim o conhecimento, não mais uma dominação definiente, e sim uma dominação aperfeiçoada da natureza, não mais o que escapa do controle humano, e sim justamente o sistema de decisões e coerções objetivas estabelecido com a era 
de munições que supre as demandas das duas partes em conflito ${ }^{10}$. De fato, as decisões que envolvem a pesquisa, normalmente, são tomadas antes que se possam vislumbrar os resultados.

Os riscos associados ao ingresso de uma nova tecnologia na sociedade costumam ser caracterizados como problemas de fronteira que tangenciam diferentes sistemas. Cada um destes responde a uma situação segundo seus próprios códigos para a definição e avaliação do risco. No caso da nanotecnologia, os sistemas científico, político, econômico e jurídico deveriam atuar em conjunto. No âmbito cientifico, o código pelo qual o problema é avaliado pode ser representado pelo binômio verdadeiro/falso, no sistema jurídico legal/ilegal, no sistema econômico propriedade/não propriedade, e no sistema político poder/não poder $^{11}$. A dificuldade reside na criação de pontes que permitam o diálogo entre os dados encontrados pelos cientistas com uma interpretação pelos tomadores de decisão, que, no nosso caso, seriam principalmente os políticos. O que se observa com novas tecnologias é que o exame sobre os riscos é realizado, em grande parte, apenas pelo sistema cientifico, e que a avaliação sobre os riscos das possíveis consequências a serem geradas pela introdução da nova tecnologia é feita, posteriormente, pelo sistema político com base nos dados científicos ${ }^{12}$. E, normalmente, esse exame é feito para referendar a escolha científica feita anteriormente ${ }^{13}$.

A seguir será analisado o tratamento dispensado aos nanowastes no ordenamento jurídico nacional e internacional.

\section{Breve definição de nanotecnologia}

Em 1958, Richard Feynman, vencedor do Prêmio Nobel de Física de 1965, proferiu uma palestra na Universidade da Califórnia, denominada There's plenty of room at the bottom. Durante a palestra, sem se utilizar da palavra nanotecnologia, afirmou que

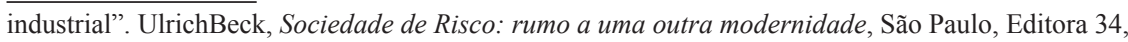
2010, pág. 275.

10 "However, the public reputation of science also leads to science being searched for arguments - being regarded more or less as munitions factory supplying both sides in ideological or political confrontations". NiklasLuhmann, Risk: a sociology theory, New Jersey, Translation Publishers, 2008, pág. 213.

${ }_{11}$ Ver mais sobre o tema nos capítulos 4 e 5 da obra de Niklas Luhman, Risk: a sociology theory, New Jersey, Translation Publishers, 2008.

12 "O monopólio da verdade do juízo científico obriga assim que os próprios afetados façam uso de todos os meios e métodos da análise científica para implementar suas demandas". UlrichBeck,Sociedade de Risco: rumoa uma outra modernidade, São Paulo, Editora 34, 2010, pág. 87.

13 "Com a política de "fatos consumados", elas sempre puderam escapar à crítica e aos debates públicos sobre o que é ou não permitido a um pesquisador. Sem dúvida, alguma, questões cientificas também são levantadas assim". UlrichBeck, Sociedade de Risco: rumo a uma outra modernidade,São Paulo, Editora 34, 2010, pág. 306. 
I have estimated how many letters there are in the Encyclopaedia, and I have assumed that each of my 24 million books is as big as an Encyclopaedia volume, and have calculated, then, how many bits of information there are (1015). For each bit I allow 100 atoms. And it turns out that all of the information that man has carefully accumulated in all the books in the world can be written in this form in a cube of material one two-hundredth of an inch wide| which is the barest piece of dust that can be made out by the human eye. So there is plenty of room at the bottom! ${ }^{14}$.

Esse discurso é considerado como marco do início do desenvolvimento da matéria, embora o termo nanotecnologia não tenha sido desenvolvido por Feynman. A origem do termo nanotechnology data de 1974, quando o professor Norio Taniguchi na Universidade de Ciências de Tóquio, empregou esse termo para descrever as tecnologias utilizadas em uma escala nanométrica, avançando, assim, os conceitos elaborados anteriomente por Feynman. Posteriormente, em 1986, a obra Engines of criation- The coming era of nanotecnology de Eric Drexler contribuiu para a evolução da nanotecnologia, nela o autor abordou a manipulação individual de átomos e moléculas em uma escala manométrica ${ }^{15}$.

A nanotecnologia pode ser compreendida por meio de duas características principais. A primeira delas é referente ao prefixo grego nannos, nano que significa anão. $\mathrm{O}$ nanômetro é uma medida correspondente à bilionésima parte do metro, ou seja, um nanômetro $=10^{-9}$ (do metro). A segunda característica refere-se ao conjunto de técnicas utilizadas a fim de manipular a matéria na escala de átomos e moléculas. Para ser visualizada requer avançados microscópios, Sacanning Tunneling Microscope (STM) e Scanning Probe Microscope (SPM) ${ }^{16}$.

Observa-se, a partir de uma análise da literatura, que existem diversas definições para nanotecnologia. Destacam-se iniciativas internacionais e regionais relevantes para normalizar o termo, tais como as empreendidas pela InternacionalOrganization Standardization (ISO), pela Internacional Electrotechnical Commission, pela European Standardisation Committee. Dentre as iniciativas de normalização, a ISO tem assumido internacionalmente a liderança, com a criação, em 2005 , de um comitê técnico ISO TC $229{ }^{17} \mathrm{O}$ relatório da ISO TC 229 traz a definição de nanotecnologia, nos seguintes termos:

Standardization in the field of nanotechnologies that includes either or both of the following:

${ }^{14}$ Richard P. Feynman, Plenty of Room at the Bottom, Dec. 1959. Disponível em: <http://www. pa.msu.edu/ yang/RFeynman_plentySpace.pdf>. Acesso em 27 out. 2014.

15 Eric Drexler, Engines of criation- The coming era of nanotechnology,1986, pág. 147.

16 Paulo Martins, Nanotecnologia e meio ambiente para uma sociedade sustentável,"Estudios sociales", 17 (2009), no 34, México.

17 JoséJailtonDamasceno,AnaR.Ribeiro, LucieneBBalottin, JoséMauroGranjeiro,Nanometrologiadesafios para a regulação sanitária,"VigilânciaSanitária",1(4),(2013), pág. 111. 
1. Understanding and control of matter and processes at the nanoscale, typically, but not exclusively, below 100 nanometres in one or more dimensions where the onset of size-dependent phenomena usually enables novel applications;

2. Utilizing the properties of nanoscale materials that differ from the properties of individual atoms, molecules, and bulk matter, to create improved materials, devices, and systems that exploit these new properties ${ }^{18}$.

$\mathrm{Na}$ União Europeia, o nanomaterial tem sido definido como sendo um material "de origem natural, incidental ou manufaturado contendo partículas em estado não-ligado, aglomerado ou agregado para os quais $50 \%$ ou mais das partículas da distribuição por número, ou uma ou mais das dimensões externas, situa-se na faixa entre 1 e $100 \mathrm{~nm}$ "19. A definição de nanotecnologia mais divulgada e compartilhada por diferentes organizações governamentais refere-se a essa tecnologia como sendo: “a compreensão e controle da matéria na escala nanométrica, em dimensões entre cerca de 1 e 100 nanometros (nm), onde fenômenos únicos permitem novas aplicações" ${ }^{20}$.

Nesse artigo, optou-se empregar a definição de nanomaterial para se referir também ao nanomaterial manufaturado ${ }^{21}$. Não será o enfoque deste trabalho o tratamento de nanomateriais de origem natural.

A nanotecnologia tem se desenvolvido de modo progressivo nos últimos anos em decorrência dos altos investimentos em pesquisa realizados. Em 2001, os Estados Unidos disponibilizavam aproximadamente US\$ 464 milhões, já em 2007 esse patamar alcançou cerca de US\$ 1,5 bilhões com pesquisas destinadas à nanotecnologia ${ }^{22}$.No Brasil, estimam-se investimentos de R \$ 440 milhões entre 2013 a 2014, segundo informações do Ministério da Ciência e Tecnologia ${ }^{23}$.

${ }^{18}$ International Organization for Standardization, ISO/TC 229Nanotechnologies.Disponível em: $<$ http://www.iso.org/iso/iso_technical_committee?com mid=381983>. Acesso em: 27 out. 2014.

19 Agencia Brasileira de Desenvolvimento Industrial,Nanotecnologia na área da saúde: mercado, segurançaeregulação, Rio de Janeiro, 2013, pág. 8 .Disponível em: <http://www3.eco.unicamp.br/ neit/image s/stories/Setoriais_fase_II/relatorio-nanotecnologia.pdf > . Acesso em: 7 out. 2014.

${ }^{20}$ Nesse sentido: National Institutes for Health (NIH). Agencia Brasileira de Desenvolvimento Industrial. Nanotecnologia na área da saúde: mercado, segurança e regulação, Rio de Janeiro, 2013, pág. 7. Disponível em: < http://www3.eco.unicamp.br/neit/images/stories/Setoriais_fase_II/relatorionanotecnologia.pdf>. Acesso em: 7 out. 2014.

21 Existem duas classificações possíveis para nanopartículas: nanopartículas de origem natural e as nanopartículas antropogênicas. As primeiras são de origem biológica, como vírus e bactérias, e outras são de origem mineral, como a exemplo do sal marinho, da poeira vulcânica e de algumas moléculas, como a magnetita biogênica e a proteína ferritina, que são encontradas no interior de organismos primitivos. As nanopartículas antropogênicas estão relacionadas aos processos industriais ou a atividades que envolvem a queima de combustíveis fósseis. Dessa forma, temos dois tipos de nanopartículas antropogênicas: as nanopartículas engenheiradas e as nanopartículas não engenheiradas. Matheus PPaschoalino, Glauciene P. S.Marcone,Wilson F. Jardim,Os nanomateriais e a questão ambiental,“Química Nova”, 33, 2 (2010), págs.421-430.

22 Ibidem.

${ }^{23}$ Ministério da Ciência e Tecnologia e Inovação (MCTI), Brasil,Governo vai investir R\$ 440 milhões emnanotecnologia. Disponível em: <www.ebc.com.br/tecnologia/2013/.../governo-vaiinvestir-r-440-milhoes.>. Acesso em: 22 jul. 2014. 
Diversos benefícios podem ser relatados nas mais diversas áreas de aplicação das nanotecnologias. Um exemplo bastante promissor diz respeito à evolução da medicina, conhecido também como "Nanomedicina"; tal termo refere-se ao uso de novos nanomateriais e ferramentas de nanotecnologia em áreas médicas, principalmente diagnóstico e tratamento. Dentre as contribuições imagináveis no campo da medicina, reporta-se: “(...) o aumento da qualidade de vida e sua duração, através de nanossensores incorporados ao próprio organismo e que viajam pelo mesmo como se fossem vírus pelo sangue, onde poderão detectar doenças antes que se expandam"24.

Outro destaque é o mercado de nanocosméticos; a maior parte das patentes nessa área refere-se aos cuidados com a saúde, pele e produtos para cabelo. Podemos encontrar a nanotecnologia no dia a dia dos consumidores, por meio de cosméticos e produtos para higiene pessoal, destacando-se entre eles: protetores solar, cremes antirrugas, xampus, condicionadores, desodorantes, esmaltes, maquiagens.

Outros setores também merecem destaque: a) no setor automobilístico: utilização de pinturas especiais (não riscam, autolimpantes), catalisadores para conversores catalíticos; eletrônica e tecidos antibacterianos; b) no setor de energia: desenvolvimento de sistemas fotovoltáicos; células solares; grids de energia; baterias; pás para geradores; c) no setor de iluminação: desenvolvimento de leds baseados em quantum dots para iluminação pública, domiciliar e automobilística; d) no setor de esportes: raquetes de tênis (nanotubos de carbono); roupas esportivas antitranspirantes e antibactericidas; calçados para esportes; quadros para bicicletas; tacos de golfe; luvas para prática de esportes; e) na indústria têxtil: tecidos resistentes a sujidades (efeito lótus); tecidos antibactericidas; tecidos técnicos e não tecidos; f) embalagens com propriedades de barreira (umidade e gases) à base de nanocompósitos; embalagem inteligentes sensíveis a gases de decomposição de alimentos; recipientes bactericidas (prata) a fim de guardar alimentos perecíveis ${ }^{25}$.

Alguns benefícios das nanotecnologias podem ser esperados para a melhoria do meio ambiente: a) prevenção de poluição ou danos indiretos ao meio ambiente. Por exemplo, o uso de nanomateriais calatílicos pode aumentar a eficiência e seletividade de processos industriais, resultando em aproveitamento mais eficiente das matérias-primas e um consumo menor de energia, além de menor produção de resíduos indesejáveis; b) tratamento ou remediação de poluição, a exemplo da coleta das partículas e da remoção de poluentes, facilitada pelo uso de nanopartículas magnéticas; c) detecção e monitoramento de poluição

\footnotetext{
${ }^{24}$ Rafael LuizFerronato,Nanotecnologia, ambiente e direito: desafios para a sociedade na direção a um marcoregulatório, 2010 (111 fls.) Tese (Mestrado em Direito) Universidade Caxias do Sul, Caxias do Sul (RS), 2010. pág. 19.

${ }_{25}$ Agencia Brasileira de Desenvolvimento Industrial,Cartilha sobre nanotecnologia, Brasília, ABDI, 2011, pág. 27.
} 
com a fabricação de sensores cada vez menores, mais seletivos e sensíveis com a finalidade de detectar e monitorar poluentes orgânicos e inorgânicos no meio ambiente ${ }^{26}$.

\section{Nanotecnologias: benefícios e riscos na atual sociedade de risco}

Embora inúmeros benefícios possam ser relatados para a melhoria do meio ambiente e da saúde do homem, essas mesmas características que tornam as nanopartículas tão interessantes ao desenvolvimento da tecnologia, podem tornar-se indesejáveis quando liberadas no meio ambiente ${ }^{27}$. Um dos fatores que demonstram o potencial risco das nanopartículas é o tamanho das partículas que influencia o seu comportamento no meio ambiente, pois, mesmo sendo do mesmo elemento químico, podem comportar-se de maneira diferente, devido ao seu pequeno tamanho que facilita a difusão e o transporte na atmosfera, água e solo, dificultando a remoção por técnicas usuais de filtração ${ }^{28}$. Torna-se difícil fazer uma avaliação genérica dos riscos para saúde e meio ambiente com o uso das técnicas usuais para aferição de risco ambiental.

Com base em informações divulgadas pela Environmental Protection Agency (EPA) ${ }^{29}$, em agosto de 2014, existiam sete tipos de nanomateriais que são utilizados para consumo e que podem ser efetivamente prejudiciais à saúde e ao meio ambiente, diante da possibilidade de persistência ou bioacumalação ${ }^{30}$, como por exemplo: a) alguns estudos relataram o estresse oxidativo e alterações patológicas em espécies aquáticas, especificamente a truta, após a exposição de nano- $\mathrm{TiO} 2$; b) outros estudos compararam os efeitos tóxicos do óxido de zinco em nanopartículas (zinc oxide ( $\mathrm{ZnO}) \mathrm{NPs}$ ) e o óxido de zinco, na Dunaliella tertiolecta, um tipo de alga marinha e os resultados sugeriram que os $\mathrm{ZnO}$

${ }^{26}$ Frank Quina,Nanotecnologia e o meio ambiente: perspectivas e riscos. "QuímicaNova", vol. 27 n. 6 São Paulo, nov./dez. 2004. Disponível em: <http://www.scielo.br/scielo. php?pid=S0100-404220040006 00031\&script=sci_arttext $>$. Acesso em: 22 jul. 2014.

27 Desta forma, adverte Nogueira: “(...) uma grande variedade de nanopartículas está sendo sintetizada, processada e descartada, em proporções cada vez maiores, sem prévio conhecimento dos seus possíveis efeitos tóxicos". Patricia F. MNogueira, Iêda Maria M.Paino, Valtencir Zucolotto, Nanosilver: Propriedades, aplicações e impactos na saúde pública e meio ambiente,"Vigilância Sanitária em Debate", 1(4) (2013), pág. 60.

${ }^{28}$ Frank Quina,Nanotecnologia e o meio ambiente: perspectivas e riscos, "QuímicaNova", vol. 27 n. 6, São Paulo, nov./dez. 2004. Disponível em: <http://www.scielo.br/scielo. php?pid=S0100-404220040006 00031\&script=sci_arttext>. Acesso em: 22 jul. 2014.

${ }^{29}$ Agência Federal dos Estados Unidos de Proteção Ambiental.

${ }^{30}$ Agência Federal dos Estados Unidos de Proteção Ambiental. Os sete tipos de nanomateriais mais utilizados no consumo: carbono- based( natural or engineered), metal oxides( natural or engineered), zero-valent metals (engineered), quantum dots ( engineered), dendrimers (engineered), composite NMs ( engineered), nanosilver (engineered). Disponível em:http://www2.epa.gov/sites/production/ files/2014-03/documents/ffrrofactsheet_emerg ingcontami nant_nano materials_ja n2014_final.pdf. Acesso em: 21 out.2014. 
NPs são mais tóxicos para as algas marinhas do que em grande quantidades de $\mathrm{ZnO}^{31}$; c) outros estudos sugeriram que alguns nanomateriais, como ouro, devido ao seu pequeno tamanho, podem apresentar uma permeabilidade maior em contato com a pele, mucosas e membranas celulares, podendo ter o seu efeito tóxico potencializado ${ }^{32}$; d) Os nanomateriais baseados em carbono, como os negro de fumo (carbon black) (...)são aptos a influenciar fenômenos que ocorrem na estratosfera que podem alterar o clima, o ciclo de nuvens e o processo de destruição do ozônio ${ }^{33}$; e) $\mathrm{O}$ negro de fumo empregado em larga escala na indústria de borracha e tintas pode estar associado à inflamação pulmonar pela via inalatoria ${ }^{34}$; f) As nanoparticulas de prata podem ocasionar efeitos tóxicos sistêmicos, como, por exemplo, o sistema cardiovascular e o sistema nervoso centra $^{35}$.Por outro lado, a exposição da saúde humana aos nanomateriais (NM) poderá ocorrer em várias fases do ciclo de vida do NM, desde a síntese, produção e inclusão nos produtos (com a exposição dos trabalhadores), até a utilização desses mesmos produtos no mercado de consumo ${ }^{36} \mathrm{e}$, posteriormente essa eliminação de NM poderá acumular-se no meio ambiente, causando inevitavelmente danos á saúde humana e ao meio ambiente ${ }^{37}$.

Esses são alguns exemplos potenciais dos benefícios e riscos do uso de nanopartículas. Diante da possibilidade desses compostos alcançarem diferentes ecossistemas e causarem danos à saúde humana, recomenda-se a aplicação do princípio da precaução. A incerteza científica sobre os riscos gerados por meio da nanotecnologia justifica a aplicação do referido princípio. Nesse caso " a verdadeiro ideia de risco é a incerteza do que ainda está por

\footnotetext{
${ }^{31}$ Agência Federal dos Estados Unidos de Proteção Ambiental.Disponível em: < http://www2.epa. gov/sites/production/files/2014-03/documents/ffrrofactsheet_emergingcontaminant_nanomaterials jan2014_final.pdf. Acesso em: 21 out.2014.

32 Matheus PPaschoalino, Glauciene P. S.Marcone, Wilson FJardim, Os nanomateriais e a questão ambiental,"Química Nova”, 2 v.33 (2010).

${ }^{33}$ Ibidem.

${ }^{34}$ Ibidem.

${ }^{35}$ Patricia F. M. Nogueira, Iêda Maria M. Paino, Valtencir Zucolotto, Nanosilver: Propriedades, aplicações e impactos na saúde pública e meio ambiente,"Vigilância Sanitária em Debate", 1(4) (2013), pág.60.

${ }^{36}$ Nesse sentido, Borges, Louro, Silva esclarecem "que a presença de NM no ar pode deverse a processos de erosão de materiais fabricados ou à produção/utilização/manipulação de pósnanoparticulados em processos industriais, sendo que a via inalatória constitui a via de exposição humana mais relevante, particularmente, em contexto ocupacional. Em relação à exposição por via oral, sabe-se que os NM incorporados em alimentos, suplementos alimentares ou mesmo em embalagens alimentares, bem como os originários de solos ou águas contaminadas, poderão ser absorvidos através do intestino de mamíferos e, assim, originar, eventualmente, efeitos sistémicos. A via transdérmica é também importante, quer em termos ocupacionais quer quando se trata da utilização de produtos de cosmética e higiene pessoal contendo NM na sua composição, apesar de o conhecimento sobre a capacidade de os NM penetrarem (ou não) na pele permanecer ainda inconclusivo". Henriqueta Louro, Teresa BORGES, Maria João Silva, Nanomateriais manufaturados novos desafios para a saúde pública,"Portuguesa de Saúde Pública", 22 (2013), pág.13.

37 Henriqueta Louro, Teresa BORGES, Maria JoãoSilva, Nanomateriais manufaturados novos desafios para a saúde pública,"Portuguesa de Saúde Pública", 22 (2013), pág.3.
} 
vir com todo o progresso tecnológico e científico, risco está intimamente conectado à inovação"38. Portanto, o risco ainda não é o dano ou o prejuízo, mas a possibilidade de ocorrência.

O progresso tecnológico possui um caráter paradoxal; se por um lado gera benefícios, por outro produz externalidades negativas. Por isso, o momento atual é propício a fazer uma ponderação entre as vantagens e possíveis inconvenientes da nanotecnologia, de modo a garantir que o progresso da ciência não ameace de maneira insustentável a qualidade de vida do homem e de todo um ecossistema.

\section{Dos resíduos aos nanowastes}

A Lei 12.305/2010, que instituiu a política nacional de Resíduos Sólidos no Brasil, estabelece no artigo $3^{\circ}$, inciso XVI, o conceito de resíduo sólido que pode ser entendido como: "material, substância, objeto ou bem descartado resultante de atividades humanas em sociedade, a cuja destinação final se procede, se propõe proceder ou se está obrigado a proceder, nos estados sólido ou semissólido, bem como gases contidos em recipientes e líquidos cujas particularidades tornem inviável o seu lançamento na rede pública de esgotos ou em corpos d'água, ou exijam para isso soluções técnicas ou economicamente inviáveis em face da melhor tecnologia disponível"39.

A despeito da produção de resíduos sempre ter existido na nossa sociedade, ele passa a a ser considerado um problema com a emergência da sociedade de risco $^{40}$. Alguns fatores estão intimamente ligados à geração de resíduos: a) o aumento do consumo; b) produção de materiais artificiais; c) o desenvolvimento de novas tecnologias. O aumento do consumo de bens, direcionado para o consumismo está relacionado com a evolução da sociedade capitalista, que ao mesmo tempo incentiva o consumo e o descarte de bens. A produção de materiais artificiais está diretamente relacionada com o aumento da população e seu adensamento. "A urbanização constitui fonte de agravamento para a questão dos resíduos, por serem gerados de forma concentrada nos centros urbanos (...)"41. Por outro lado, o emprego de novas tecnologias também é capaz de gerar resíduos em decorrência do seu próprio desenvolvimento.

As atividades humanas interferem diretamente no meio ambiente e são potencialmente geradoras de resíduos. O aumento do consumo aliado ao capitalismo, o processo crescente de urbanização e o desenvolvimento de novas

\footnotetext{
38 Teresa AnconaLopez, Princípio da precaução e evolução da responsabilidade civil, São Paulo, Quartier Latin, 2010, pág. 22.

${ }^{39}$ Lei $12.305 / 2010$.

40 "Maria Alexandra de SousaAragão,O princípio do nível elevado de proteção e a renovação ecológica dodireitoambiental e dos resíduos, Almedina, Coimbra, 2006, pág. 72.

${ }^{41}$ Juliana VieiraSantos, A gestão dos resíduos sólidos urbanos: um desafio. Tese (doutorado), Faculdade de Direito do Largo São Francisco da USP, São Paulo, 2009, págs.52-53.
} 
tecnologias apresentam aspectos contraditórios: a dependência de recursos naturais, o desenvolvimento de novos materiais cada vez mais complexos e aumento de "resíduos que podem causar os mais variados tipos de poluição, causando perturbações ambientais na hidrosfera, na atmosfera, na litosfera e biosfera" ${ }^{\prime 2}$.

Em linhas gerais, é possível deduzir que os resíduos decorrem da atividade humana e são potencialmente causadores de poluição. Logo, a palavra waste, derivada da língua inglesa, significa resíduo ou desperdício e nanowaste é o resíduo decorrente de nanometeriais ${ }^{43}$.

\subsection{Nanowastes: uma mudança de paradigma}

Na literatura inglesa, o termo nanowastes pode ser compreendido como os resquícios do consumo e produção de materiais advindos da nanotecnologia e incluem nanopartículas, compósitos, misturas, metais puros e aerossóis solúveis e insolúveis ${ }^{44}$. Genericamente, o conceito de nanowastes pode ser entendido como aqueles materiais gerados a partir de um processo produtivo cuja ordem é do tamanho de nanômetros. $\mathrm{Ou}$, ainda, os resíduos dos nanoprodutos, cuja vida útil tenha chegado ao seu fim e foram descartados. Dessa forma, a geração de nanowastes abrange duas cadeias: a) as indústrias na manipulação de nanomateriais e nanoprodutos decorrentes de seu sistema produtivo; b) e os consumidores que também são responsáveis pela geração de nanowastes ao consumirem os nanoprodutos ${ }^{45}$.

Estudos demonstram o aumento exponencial de nanomateriais e nanoprodutos no mercado de consumo ${ }^{46}$, todavia, esses nanomateriais podem ter efeitos nocivos quando liberados no meio ambiente ${ }^{47}$. Dentre essas nanopartículas, destacam-se as "metálicas, incluindo as de prata (NPAg), de ouro (NPAu), de óxidos- principalmente à base de óxidos de ferro e titânio- nanopartículas poliméricas, semicondutoras ou a base de carbono" 48 .

Algumas dessas nanopartículas têm sido objeto de estudo sobre os seus

\footnotetext{
${ }^{42}$ Maria Alexandra de Sousa Aragão,Direito dos resíduos sólidos, CadernosCEDOUA, Coimbra, 2000, pág. 6.

43 Juliana VieiraSantos, $A$ gestão dos resíduos sólidos urbanos: um desafio. Tese (doutorado), Faculdade de Direito do Largo São Francisco da USP, São Paulo, 2009.

${ }^{44}$ Bystrzejewska-Piotrowska, Nanoparticles: their potential toxicity, waste and environmentalmanagement, Waste Management, "Elsevier Ltd." 9, v. 29 (2009), págs.2587-2595. Disponível em: <http://www.ncbi.nlm.nih.gov/pubmed/19427190>. Acesso em: 22 jul.2014.

${ }^{45}$ Carlos Felipe Mendoza,Laura Meraz Cabrera, Hacia la nanociencia verde nanomateriales, nanoproductos ynanorresiduos. UNAM- Universidade do México, "Materiales Avanzados", 19 (2012)2012, págs. 39-42.

${ }^{46}$ N. MUSEE, Nanowastes and the environment: potencial new waste management paradigm. "Elsevier Environment International" 37(2011), pág. 111.

${ }^{47}$ Matheus P. Paschoalino, Glauciene P. S. Marcone, Wilson F Jardim, Os nanomateriais e a questão ambiental, "Química Nova", 2 v.33 (2010), pág.421.

${ }_{48}$ Patricia F. M. Nogueira, Iêda Maria M.Paino, Valtencir Zucolotto, Nanosilver: Propriedades, aplicações e impactos na saúde pública e meio ambiente, "Vigilância Sanitária em Debate", 1(4) (2013), pág.60.
} 
possíveis efeitos tóxicos para saúde humana e para o meio ambiente. Neste artigo, não abordaremos todos os rejeitos de nanomateriais, mas citaremos alguns exemplos das nanopartículas mais comercializadas e seus possíveis efeitos no meio ambiente. Dessa forma, podemos destacar: as nanopartículas de prata (NPAg) e as de dióxido de titânio (TiO2).

Em relação às nanopartículas de prata, dados recentes demonstram sua aplicabilidade em aproximadamente $70 \%$ dos produtos na área da saúde em cosméticos; $30 \%$ restantes em outras áreas como: têxtil, eletrônicos, alimentos e bebidas. As NPAg presentes em cosméticos e produtos de higiene pessoal representam um alvo de exposição para a pele e podem atingir a circulação sistêmica em que diversos órgãos podem ser afetados como: fígado e baço. Desde 1970, alguns estudiosos relatam que a prata é considerada relativamente tóxica para o homem e para o ecossistema, uma vez que os íons de prata apresentam como característica principal a persistência no meio ambiente e podem concentra-se em vários organismos ${ }^{49}$.

No que tange ao meio ambiente, esses dados são preocupantes em função do "aumento da produção comercial de NPAg poderá levar a um acúmulo de espécies de prata em vários compartimentos ambientais com impactos negativos aos ecossistemas" ${ }^{\prime 50}$ e também podem ser descartadas no ambiente durante sua síntese, durante a fase de produção e incorporação em nanoprodutos, uso e, posteriormente, disposição final de tais produtos. Por consequência, as NPAg podem gerar um novo tipo de resíduo no meio ambiente, causando a perturbação e desequilíbrio em ecossistemas aquáticos ${ }^{51}$. $\mathrm{E}$ a interação de tais resíduos no meio ambiente não foi ainda estudada com a profundidade necessária.

As nanopartículas de $\mathrm{TiO} 2$ são utilizados na produção de tintas, revestimentos, papel, plástico, cerâmica, borracha, tinta de impressoras, revestimentos do chão, na área de cosméticos, medicamentos, como protetor solar $(\ldots)^{52}$. Esse óxido é utilizado principalmente por absorver a radiação ultravioleta nociva à pele humana e, para adquirir uma emulsão transparente, deverá possuir dimensões nanométricas ${ }^{53}$.

Recentemente, o National Institute for Occupational Safety and Health (NIOSH) recomendou limites de exposição de $0,3 \mathrm{mg} / \mathrm{m}^{3}$ de ar para o dióxido de titânio nas formas nano. Embora não existam dados atuais sobre exposição

49 Patricia F. M. Nogueira, Iêda Maria M.Paino, Valtencir Zucolotto, Nanosilver: Propriedades, aplicações e impactos na saúde pública e meio ambiente, "Vigilância Sanitária em Debate", 1(4) (2013).

${ }^{50}$ Patricia F. M. Nogueira, Iêda Maria M.Paino, Valtencir Zucolotto, Nanosilver: Propriedades, aplicações e impactos na saúde pública e meio ambiente, "Vigilância Sanitária em Debate", 1(4) (2013), pág.62.

51 Ibidem

52 Henriqueta Louro, Teresa Borges, Maria João Silva, Nanomateriais manufaturados novos desafios para asaúde pública, “Portuguesa de Saúde Pública”, 22 (2013), pág.13.

53 Matheus P Paschoalino, Glauciene P. S. Marcone, Wilson F Jardim, Os nanomateriais e a questão ambiental, "Química Nova", 2 v.33 (2010), pág.422.

Araucaria. Revista Iberoamericana de Filosofía, Política y Humanidades, año 17, no 33. Primer semestre de 2015. Pp. 183-209. ISSN 1575-6823 e-ISSN 2340-2199 doi: 10.12795/araucaria.2015.i33.08 
de trabalhadores ao dióxido de titânio, estima-se que no período compreendido entre 1981 a 1983, 2,7 milhões de trabalhadores estavam potencialmente expostos a esse óxido, em especial pela via inalatória. Entretanto, estudos realizados pela NIOSH com exposição dos trabalhadores ao dióxido de titânio (em pó) não evidenciaram um risco acrescido de mortalidade ou morbilidade por cancro do pulmão ${ }^{54}$. Nesse sentido, observa-se a utilização de limites de tolerância. Beck entende que tais limites são "linhas de recuo de uma civilização que se aprovisiona com um excesso de materiais poluentes e tóxicos. Por meio dos limites de tolerância, a exigência que na verdade pareceria óbvia, de não envenenar, é refutada como utópica". ${ }^{5}$

Diante da existência de riscos que os nanomateriais podem causar à saúde humana e a todo um ecossistema, deve-se aplicar o princípio da precaução que deverá gerenciar todas as fases do ciclo de vida dos nanomateriais (produção, consumo, descarte e tratamento dos nanowastes). Esse gerenciamento dos nanomateriais deverá levar em consideração as rotas de absorção que estão sujeitos os organismos receptores: que podem dar-se através do nível celular, pela via inalatória e através da ingestão involuntária de nanopartículas. Dessa forma, recomenda-se a caracterização adequada de cada nanomaterial segundo alguns parâmetros, tais como o tamanho médio das partículas, a área e a composição química superficial ${ }^{56}$.

\subsection{A regulação dos resíduos e as normas reflexas à temática dos nanowastes: breve enfoque UE e Brasil}

O primeiro tratamento jurídico dado aos resíduos é o da res derelictae, ou seja, o abandono de coisas móveis. ${ }^{57} \mathrm{O}$ tema é antigo, "há mais de vinte séculos, os interesses em conflito, que o direito devia hierarquizar ou compatibilizar, eram os interesses de apropriação de vários achadores de uma coisa abandonada que aspiravam a apropriar-se dela" 58 .

$\mathrm{O}$ regime jurídico da res derelictae mostrou-se inapropriado para a atual sistemática dos resíduos, uma vez que dispõe acerca do abandono como modalidade de extinção do direito de propriedade. No período pós Revolução Industrial, o regime jurídico dos resíduos ganha força no enfoque do direito de vizinhança. E, com a mudança de paradigma de uma sociedade industrial, para

\footnotetext{
${ }^{54}$ Henriqueta Louro, Teresa Borges, Maria João Silva, Nanomateriais manufaturados novos desafios para asaúde pública, "Portuguesa de Saúde Pública”, 22 (2013), pág.5.

55 Ulrich Beck, Sociedade de Risco: rumo a uma outra modernidade, São Paulo, Editora 34, 2010, pág. 78.

${ }_{56}$ Matheus P Paschoalino, Glauciene P. S. Marcone, Wilson F Jardim, Os nanomateriais e a questão ambiental, "Química Nova", 2 v.33 (2010), págs. 423-425.

${ }^{57}$ Patrícia Faga Iglecias Lemos, Resíduos sólidos e responsabilidade civil pós-consumo, São Paulo, Revista dosTribunais, 2012, pág. 84.

${ }_{58}$ Maria Alexandra de Sousa Aragão, O princípio do nível elevado de proteção e a renovação ecológica do direito ambiental e dos resíduos, Almedina, Coimbra, 2006, pág. 74.
} 
uma sociedade pós-industrial, os resíduos passam a ganhar uma nova conotação ambiental, "a configuração do chamado bem socioambiental"59.

No que tange ao regime jurídico nanowastes, não existe uma regulamentação específica sobre o tema, seja no espaço internacional ou nacional. O que existe é um conjunto de normas reflexas que poderiam ser adaptadas à matéria. No direito ambiental internacional, existe alguns tratados que poderiam ser aplicados às nanotecnologias e à problemática dos nanowastes. Alguns desses tratados merecem destaque $^{60}$ : a) convenção sobre Diversidade Biológica, de 1992 e o seu Protocolo de Cartagena sobre Biossegurança, de $2000^{61}$; b) a Convenção da Basileia sobre Movimentos Transfronteiriços de Resíduos Perigosos e seu Depósito, de 198962; c) a Convenção de Estocolmo sobre Poluentes Orgânicos Persistentes, de 200163; d) a Convenção de Roterdã sobre o Procedimento de

${ }^{59}$ Patrícia Faga Iglecias Lemos, Residuos sólidos e responsabilidade civil pós-consumo, São Paulo, Revista dosTribunais, 2012, págs. 85-87.

${ }^{60}$ Wilson Engelmann, Airton Guilherme Berger Filho, As nanotecnologias e o direito ambiental: a mediação entre custos e beneficios na construção de marcos regulatórios, "RDA”, 59 (2010), págs. 60-61.

${ }^{61}$ Em 29 de janeiro de 2000, a Conferência das Partes da Convenção sobre Diversidade Biológica (CDB) adotou seu primeiro acordo suplementar conhecido como Protocolo de Cartagena sobre Biossegurança. Este Protocolo visa assegurar um nível adequado de proteção no campo da transferência, da manipulação e do uso seguros dos organismos vivos modificados (OVMs) resultantes da biotecnologia moderna que possam ter efeitos adversos naconservação e no uso sustentável da diversidade biológica, levando em conta os riscos para a saúde humana, decorrentes do movimento transfronteiriço. O Protocolo entrou em vigor em 11 de setembro de 2003, noventa dias após a entrega do $50^{\circ}$ instrumento de ratificação. Disponível em: <http:/www.mma.gov.br/biodive rsidade/convencao-da-diversidadebiologica/protocolo-de-cartagena-sobre-biosseguranca> . Acesso em 12 out. 2014.

${ }^{62}$ A Convenção de Basileia sobre o Controle de Movimentos Transfronteiriços de Resíduos Perigosos e seu Depósito, foi concluída em Basileia, Suíça, em 22 de março de 1989. Ao aderir à convenção, o governo brasileiro adotou um instrumento que considerava positivo, uma vez que estabelece mecanismos internacionais de controle desses movimentos, baseados no princípio do consentimento prévio e explícito para a importação, exportação e o trânsito de resíduos perigosos. A convenção procura coibir o tráfico ilegal e prevê a intensificação da cooperação internacional para a gestão ambientalmente adequada desses resíduos. A convenção foi internalizada na íntegra por meio do Decreto $N^{o} 875$, de 19 de julho de 1993, sendo também regulamentada pela Resolução Conama N $^{\circ}$ 452, 02 de julho de 2012. Com a promulgação da Política Nacional de Resíduos Sólidos - PNRS, Lei $\mathrm{n}^{\circ} 12.305$, de 2 de agosto de 2010, foi proibida definitivamente a importação de resíduos perigosos conforme artigo transcrito a seguir: Art. 49. É proibida a importação de resíduos sólidos perigosos e rejeitos, bem como de resíduos sólidos cujas características causem dano ao meio ambiente, à saúde pública e animal e à sanidade vegetal, ainda que para tratamento, reforma, reúso, reutilização ou recuperação. Disponível em: <http://www.mma.gov.br/cidades-sustentaveis/residuos-perigosos/ convencao-de-basileia>. Acesso em: 12 out. 2014.

${ }^{63}$ Essa Convenção destaca-se por incluir no seu escopo a obrigação dos países-Parte de adotarem medidas de controle relacionadas a todas as etapas do ciclo de vida $3 / 4$ produção, importação, exportação, disposição e uso das substâncias classificadas como Poluentes Orgânicos Persistentes (Pops). Os Poluentes Orgânicos Persistentes 3/4 POPs são substâncias químicas de alta persistência, capazes de serem transportados por longas distâncias, e de se acumularem em tecidos gordurosos dos organismos vivos, sendo tóxicos para o homem e para os animais. Os POPs circulam globalmente e podem causar danos nos diversos ambientes por onde passam. A Convenção Pops entrou em vigor em 2004, após 50 países ratificarem-na. Atualmente, 164 Partes integram a Convenção de Estocolmo. O Brasil aprovou o texto da Convenção por meio do Decreto Legislativo n ${ }^{\circ} 204$, de 7 de maio de 2004, e promulgou o texto da Convenção em 2005, via o Decreto n ${ }^{\circ} 5.472$, de 20 de junho de 2005. Disponível em: <http://www.mma.gov.br/>. Acesso em: 12 out 2014. 
Consentimento Prévio Informado, Aplicado a Certos Agrotóxicos e Substâncias Químicas Perigosas Objeto de Comércio Internacional - PIC, de $1998^{64}$.

No direito comunitário, algumas normas poderiam ser suscetíveis de serem aplicadas ao assunto. ${ }^{65}$ As disposições constantes na Diretiva 2008/1/CE do Parlamento Europeu e do Conselho de 15 de janeiro de 2008, relativa à prevenção e controle integrado da poluição. Essa Diretiva ${ }^{66}$ estabelece um enquadramento geral para a prevenção e controle integrado da poluição, baseado no princípio do poluidor-pagador e na ação preventiva e traz alguns conceitos importantes como a definição de substancia ${ }^{67}$ e de poluiçã ${ }^{68}$, que poderiam ser aplicadas "a generalidade dos produtos contendo nanopartículas sintéticas" $"$.

Qualquer pessoa física ou jurídica que se utilize da manipulação de nanomateriais estaria obrigada a adotar medidas de caráter preucacional na disposição final dos nanowastes, de forma a proteger a saúde e segurança dos trabalhadores, consumidores e a proteção de todo um ecossistema. ${ }^{70}$

${ }^{64}$ A Convenção de Roterdã sobre o Procedimento de Consentimento Prévio Informado Aplicado a Certos Agrotóxicos e Substâncias Químicas Perigosas Objeto de Comércio Internacional -PIC foi adotada em setembro de 1998 e entrou em vigor em 24 de fevereiro de 2004, quando 50 países a ratificaram. O Brasil assinou a Convenção em 1998 e aprovou seu texto por meio do Decreto Legislativo no 197 , de 7 de maio de 2004. A promulgação da Convenção de Roterdã no Brasil se deu através do Decreto $\mathrm{n}^{\circ}$ 5.360, de 31 de janeiro de 2005. Disponível em: < http://www.mma.gov.br/>. Acesso em: 12 out. 2014.

65 Helena Pereira de Melo, A aplicação do princípio da precaução á nanotecnologia, " FDUP Faculdade de Direito da Universidade do Porto", 7 (2010), pág. 24.

${ }^{66}$ Ibidem.

67 Sob essa perspectiva, o disposto no $n^{\circ} 1$ do artigo $2^{\circ}$, da Diretiva 2008/1/CE entende como "«Substância», quaisquer elementos químicos e seus compostos, com excepção da substâncias radioactivas, na acepção da Directiva 96/29/Euratom do Conselho, de 13 de maio de 1996, que fixa as normas de segurança de base relativas à protecção sanitária da população e dos trabalhadores contra os perigos resultantes das radiações ionizantes (1), e dos organismos geneticamente modificados, na acepção da Directiva 90/219/CEE do Conselho, de 23 de abril de 1990, relativa à utilização confinada de microrganismos geneticamente modificados (2) e da Directiva 2001/18/CE do Parlamento Europeu e do Conselho, de 12 de março de 2001, relativa à libertação deliberada no ambiente de organismos geneticamente modificados." U.E. Diretiva 2008/1/CE do Parlamento Europeu e do Conselho de janeiro de 2008 relativa à prevenção e controle integrado da poluição, art. 2.1.

68 «Poluição», a introdução directa ou indirecta, por acção humana, de substâncias, vibrações, calor ou ruído no ar, na água ou no solo, susceptíveis de prejudicar a saúde humana ou a qualidade do ambiente e de causar deteriorações dos bens materiais ou deterioração ou entraves ao usufruto do ambiente ou a outras utilizações legítimas deste último;” E. Diretiva 2008/1/CE do Parlamento Europeu e do Conselho de janeiro de 2008 relativa à prevenção e controle integrado da poluição, art. 2.2.

69 Helena Pereira de Melo, A aplicação do princípio da precaução á nanotecnologia, "FDUP Faculdade de Direito da Universidade do Porto", 7 (2010), pág. 24.

${ }^{70}$ Qualquer pessoa singular ou coletiva que possua instalação que labore no âmbito das aludidas indústrias, tem a obrigação de adotar "todas as medidas preventivas adequadas contra a poluição, designadamente mediante a utilização das melhores técnicas disponíveis”, todas as medidas "necessárias para prevenir os acidentes e limitar os seus efeitos" e, aquando da desativação da instalação, a tomar as medidas necessárias para evitar "qualquer risco de poluição e para voltar a pôr o local da exploração em estado satisfatório". O princípio da precaução opera aqui, como salienta Maria Alexandra Aragão, como um "princípio in dubiopro ambiente". Helena Pereira de MELO, $A$ aplicação doprincípio da precaução á nanotecnologia, "FDUP Faculdade de Direito da Universidade do Porto", 7 (2010), pág. 25.

Araucaria. Revista Iberoamericana de Filosofía, Política y Humanidades, año 17, $\mathrm{n}^{\circ} 33$. Primer semestre de 2015. Pp. 183-209. ISSN 1575-6823 e-ISSN 2340-2199 doi: 10.12795/araucaria.2015.i33.08 
Outra norma que poderia ser utilizada em relação ao ciclo de vida dos nanoprodutos é a Diretiva 2006/12/CE do Parlamento Europeu e do Conselho de 5 de abril de 2006 relativa aos resíduos: $\mathrm{O}$ artigo $4^{\circ}$ determina que "Os Estados-Membros tomarão as medidas necessárias para garantir que os resíduos sejam valorizados ou eliminados sem pôr em perigo a saúde humana e sem utilizar processos ou métodos susceptíveis de agredir o ambiente e, nomeadamente: Sem criar riscos para a água, o ar, o solo, a fauna ou a flora (...)". Percebe-se aqui o interesse do legislador europeu em não se precisar o tipo de resíduos, mas a responsabilidade dos Estados quanto à gestão dos riscos do seu descarte. A Diretiva 2008/98/ CE busca estabelecer o enquadramento legal de resíduos, dispondo que o produtor de resíduos é "qualquer pessoa cuja actividade produza resíduos (produtor inicial dos resíduos) ou qualquer pessoa que efectue operações de pré-processamento, de mistura ou outras, que conduzam a uma alteração da natureza ou da composição desses resíduos" ${ }^{\prime \prime}$.

Sem a pretensão de esgotar o assunto, outras Diretivas do Parlamento Europeu e do Conselho poderiam servir direta ou indiretamente na regulação dos nanowastes. Em relação à análise conjugada das Diretivas do Parlamento Europeu, alguns juristas ${ }^{72}$ entendem que os nanowastes devem ser qualificados do ponto de vista jurídico como resíduos perigosos, em obediência aos princípios gerais de proteção do meio ambiente, da sustentabilidade e da precaução. Nesse aspecto, poder-se-ia questionar se é necessária à adoção de normas com novos requisitos de higiene e segurança para empresas na eliminação dos nanowastes? ${ }^{73}$

No Brasil ${ }^{74}$, a problemática em torno dos nanowastes também é nova, buscase, por meio da Lei da Política Nacional de Resíduos Sólidos, Lei 12.305/2010

${ }^{71}$ Art. 3.5 da Directiva 2008/08/CE do Parlamento Europeu e do Conselho de 19 de novembro de 2008

${ }_{72}$ Helena Pereira de Melo, A aplicação do princípio da precaução á nanotecnologia, "FDUP Faculdade de Direito da Universidade do Porto", 7 (2010), pág. 27.

${ }^{73}$ Ibidem.

${ }^{74}$ No Brasil existem quatro projetos de lei na tentativa de regulamentar as nanotecnologias. O primeiro projeto de lei destinado à regulamentação das nanotecnologias, data de 2005, Projeto de Lei da Câmara $n^{\circ} 5076 / 2005$, que pretendia tratar sobre a Política Nacional de Nanotecnologia, o incentivo à pesquisa e o desenvolvimento tecnológico e o controle, pelo Poder Público dos riscos e impactos decorrentes destas atividades, entre outras previstas nessa lei; esse projeto foi arquivado desde novembro de 2008. O segundo projeto de lei, data do ano de 2010, Projeto de Lei do Senado ${ }^{\circ}$ 131/2010, que pretendia alterar o Decreto- Lei $n^{\circ}$ 986, de 21 de outubro de 1969 (que institui normas básica sobre alimentos), e a Lei $\mathrm{n}^{\circ} 6.360$, de 23 de setembro de 1976 (que dispõe sobre a vigilância sanitária a que ficam sujeitos os medicamentos, as drogas, os insumos farmacêuticos e correlatos, cosméticos, saneantes e outros produtos, e dá outras providencias), para determinar que rótulos, embalagens, etiquetas, bulas e materiais publicitários de produtos elaborados utilizando recursos da nanotecnologia contenham informação sobre esse fato; esse projeto está arquivado desde agosto de 2013. O terceiro Projeto de Lei da Câmara $n^{\circ} 5.133 / 2013$ que regulamenta a rotulagem de produtos da nanotecnologia e de produtos quefazem uso da nanotecnologia; esse projeto de lei encontra-se em fase de tramitação na Câmara dos Deputados. E, finalmente, o quarto Projeto de Lei nº 6.741/2013, que se encontra em fase de tramitação. 
adaptar a matéria. Em 2013, foi proposto um projeto de Lei da Câmara dos Deputados $\mathrm{n}^{\mathrm{o}}$ 6.741/2013, que pretende dispor sobre a Política Nacional de Nanotecnologia, a pesquisa, a produção, o destino de rejeitos e o uso da nanotecnologia no país, e dá outras providências. No seu artigo 13, prevê que: os rejeitos da nanotecnologia devem ser submetidos ao estabelecido no artigo 20 da Lei $\mathrm{n}^{\mathrm{o}}$ 12.305, de 02 de agosto de 2010, que institui a Política Nacional de Resíduos Sólidos, ou seja, a priori, os rejeitos da nanotecnologia, quanto à periculosidade, podem ser classificados como: a) resíduos perigosos (aqueles que, em razão de suas características de inflamabilidade, corrosividade, reatividade, toxidade, patogenicidade (...) apresentam significativo risco á saúde pública ou á qualidade ambiental, de acordo com a lei, regulamento ou norma técnica ou b) resíduos não perigosos (aqueles não enquadrados na alínea "a").

A Lei n ${ }^{\circ} 12.305 / 2010$, no seu artigo 13, incisos I e II, prevê que os resíduos sólidos podem ser classificados quanto à origem ou periculosidade. Para os efeitos dessa Lei $^{75}$, os resíduos sólidos têm a seguinte classificação: I- quanto á origem: a) resíduos domiciliares: os originários de atividades domésticas em residências urbanas; b) resíduos de limpeza urbana: os originários da varrição, limpeza de logradouros e vias públicas e outros serviços de limpeza urbana; c) resíduos sólidos urbanos: os englobados nas alíneas "a" e "b"; d) resíduos de estabelecimento comerciais e prestadores de serviços: os gerados nessas atividades, excetuados os referidos nas alíneas "b", "e", "g", "h" e "j"; e) resíduos dos serviços públicos de saneamento básico: os gerados nessas atividades, excetuados os referidos na alínea "c"; f) resíduos industriais: os gerados nos processos produtivos e instalações industriais; g) resíduos de serviços de saúde: os gerados nos serviços de saúde, conforme definido em regulamento ou em normas estabelecidas pelos órgãos do Sisnama e do SNVS; h) resíduos da construção civil: os gerados nas construções, reformas, reparos e demolições de obras de construção civil, incluídos os resultantes da preparação e escavação de terrenos para obras civis; i) resíduos agrossilvopastoris: os gerados nas atividades agropecuárias e silviculturais, incluídos os relacionados a insumos utilizados nessas atividades; j) os resíduos de serviços de transporte: os originários de portos, aeroportos, terminais alfandegários, rodoviários e ferroviários e passagens de fronteira; k) resíduos de mineração: os gerados na atividade de pesquisa, extração ou beneficiamento de minérios; II- a) resíduos perigosos: aqueles que, em razão de suas características de inflamabilidade, corrosividade, reatividade, toxicidade, patogenicidade, carcinogenicidade, teratogenicidade e mutagenicidade, apresentam significativo risco à saúde pública ou à qualidade ambiental, de acordo com lei, regulamento ou norma técnica; b) resíduos não perigosos: aqueles não enquadrados na alínea "a".

${ }^{75}$ Ministério de Meio Ambiente, Brasil. Disponível em <http://www.sinir.gov.br/web/guest/ residuos-solidos-urbanos>. Acesso em: 12 out 2014.

Araucaria. Revista Iberoamericana de Filosofía, Política y Humanidades, año 17, $\mathrm{n}^{\circ} 33$. Primer semestre de 2015. Pp. 183-209. ISSN 1575-6823 e-ISSN 2340-2199 doi: 10.12795/araucaria.2015.i33.08 
Em relação à análise da Lei 12.305/2010, os rejeitos nanotecnológicos poderiam ser classificados como perigosos ou não, a depender dos riscos potenciais à saúde e ao meio ambiente. Atualmente, a regulamentação existente a fim de verificar a periculosidade dos resíduos é dada pelo conjunto de normas técnicas NBR 10004, 10005 e 10006 da Associação Brasileira de Normas Técnicas $^{76 .}$ É imprescindível que estudos científicos possam avançar para determinar o grau de toxidade dos nanomateriais, a fim de possibilitar a gestão e o gerenciamento adequado dos nanowastes, de acordo com a lei, regulamento ou normas técnicas apropriadas à temática.

Conclui-se que, apesar de existirem normas jurídicas reflexas no âmbito internacional e nacional, como no caso os tratados, as Diretivas do Parlamento Europeu e do Conselho, a Lei 12.305/2010 e as diversas resoluções do Conselho Nacional do Meio Ambiente (CONAMA) no Brasil, não existe um tratamento diferenciado para a problemática dos nanowastes. Em suma, não é claro se as normas jurídicas existentes são adaptáveis à proteção do meio ambiente e da saúde humana ${ }^{77}$, diante da especificidade e pluralidade de nanomateriais atualmente comercializado.

\section{O princípio da precaução como gestor dos riscos das nanotecnologias}

Durante muitos anos, o princípio da precaução pertenceu ao direito ambiental, sua origem está no conceito alemão do Vorsorgeprinzip, conforme previsão do artigo $5^{\circ}$ da lei federal sobre controle de emissões. O princípio da precaução é abordado a partir de uma dupla dimensão: material e instrumental. Na dimensão material “(...) as consequências distantes tanto em tempo como em lugar, danos a bens particulares sensíveis, meros distúrbios e pouca probabilidade de dano devem ser investigados na avaliação do risco"78. Enquanto, a dimensão instrumental “ (...) refere-se ao arsenal de medidas pertinentes" ${ }^{\text {"79 }}$. Logo em seguida, o princípio da precaução foi adaptado para o direito da União Europeia, com algumas diferenças do direito alemão e incorporado ao direito internacional.

Podemos encontrar o princípio da precaução na Declaração de Estocolmo sobre Meio Ambiente Humano, reconhecendo a necessidade de salvaguardar

${ }^{76}$ Beatriz Souza Costa, José Cláudio Junqueira Ribeiro, Gestão e gerenciamento de resíduos sólidosDireitos edeveres, Lumen Juris, Rio de Janeiro, 2013, pág. 24.

${ }^{77}$ Wilson Engelmann, Airton Guilherme Berger Filho, As nanotecnologias e o direito ambiental: a mediação entre custos e beneficios na construção de marcos regulatórios, "RDA", 59 (2010).

${ }^{78}$ Gerd Winter, A natureza jurídica dos princípios ambientais em direito internacional, direito da Comunidade Europeia e direito nacional, [em, Sandra Akemi Shimada Kishi, Solange Teles Silva, Ines Virginia Prado Sores,coord.: Desafios do direito ambiental no século XXI: Estudos em homenagem a Paulo Affonso Leme Machado. São Paulo, Malheiros, 2005], pág. 144.

${ }^{79}$ Ibidem. 
os recursos naturais, por meio de um planejamento cauteloso, e gerenciamento para o benefício das futuras gerações. Considerada uma inovação importante da Declaração do Rio, cabe ressaltar, que o princípio da precaução não surge durante a Conferência das Nações Unidas sobre Meio Ambiente e Desenvolvimento. Ele já havia sido implicitamente enunciado na Carta Mundial da Natureza adotada pela Assembleia Geral das Nações Unidas em 1982, no preâmbulo da Convenção de Viena de 1985 e no Protocolo de Montreal de 1987. A partir de 1992, ele passa a integrar inúmeros tratados dentre eles: a ConvençãoQuadro das Nações Unidas sobre Mudanças Climáticas e a Convenção sobre Diversidade Biológica, ambas assinadas em $1992^{80}$.

O princípio da precaução pode ser entendido como:

(...) aquele que trata das diretrizes e valores do sistema de antecipação de riscos hipotéticos, coletivos ou individuais, que estão a ameaçar a sociedade ou seus membros com danos graves e irreversíveis e sobre os quais não há certeza científica; esse princípio exige a tomada de medidas drásticas e eficazes com o fito de antecipar o risco suposto e possível, mesmo diante da incerteza ${ }^{81}$.

No direito brasileiro, o princípio da precaução encontra fundamento no artigo 225, parágrafo $1^{\circ}, \mathrm{V}$ da Constituição da República Federativa do Brasil de 1988, que assim prevê: “(...) controlar a produção, a comercialização e o emprego de técnicas, métodos e substância que comportem risco para a vida, a qualidade de vida e o meio ambiente" (BRASIL, 1988). Esse princípio também se encontra expresso na Lei de Biossegurança ${ }^{82}$, Lei $\mathrm{n}^{\circ} 11.105 / 2005$, na parte final do caput do seu artigo $1^{\circ}$ quando faz referência explícita à observância do princípio da precaução para o meio ambiente.

Não existe um consenso sobre os elementos constitutivos do princípio da precaução. Nesse artigo, serão abordados os pressupostos apresentados pela professora Alexandra Aragão no trabalho sobre novos riscos e incerteza científica. Porém, alguns elementos constitutivos do princípio da precaução são recorrentes:

${ }^{80}$ Liziane Paixão Silva Oliveira, A Convenção sobre Diversidade Biológica e o princípio da soberania, Dissertação de Mestrado, Universidade de Brasília, Pós-Graduação em Direito, 2006, pág.166. Disponível em: <http://bdtd.bce.unb.br/tedesimplificado/tde_busca/arquivo. php? codArquivo=4379>. Acesso em: 27 jun. 2014,

${ }_{81}$ Teresa Ancona Lopez, Princípio da precaução e evolução da responsabilidade civil, São Paulo, Quartier Latin, 2010, pág. 103.

${ }_{82} \mathrm{O}$ artigo $1^{\circ}$ da Lei $n^{\circ} 11.105 / 2005$ estabelece "normas de segurança e mecanismos de fiscalização sobre a construção, o cultivo, a produção, a manipulação, o transporte, a transferência, a importação, a exportação, o armazenamento, a pesquisa, a comercialização, o consumo, a liberação no meio ambiente e o descarte de organismos geneticamente modificados- OGM e seus derivados, tendo como diretrizes o estímulo ao avanço científico na área de biossegurança e biotecnologia, a proteção á vida e á saúde humana, animal e vegetal, e a observância do princípio da precaução para a proteção do meio ambiente" (BRASIL, 2005). 
a) indicação de risco de danos sérios e irreversíveis; b) diante da insuficiência das informações científicas inexistentes, inconclusivas ou incertas; c) que impõe ao poder público e a sociedade o dever de ação antecipada para, na medida do possível, controlar ou evitar o dano ao meio ambiente e á saúde humana ${ }^{83}$.

O primeiro pressuposto para aplicação do princípio precaução são os "novos riscos". A recente preocupação com a descoberta de diferentes tipos de nanomateriais e o desenvolvimento de novos tipos de nanoprodutos que se encontram em fase de comercialização têm provocado ampla discussão acadêmica sobre os riscos que esses novos produtos podem causar à saúde humana e ao meio ambiente. "A preocupação em relação à toxidade das nanopartículas reside no fato de que estas nunca foram produzidas e utilizadas em produtos comerciais em tão larga escala (...)" ${ }^{\text {84 }}$. Os riscos com a utilização desses produtos ainda são desconhecidos pela ciência e não se pode ficar " à espera de provas irrefutáveis e do consenso científico geral em torno delas" ${ }^{85}$.

O princípio da precaução destina-se a regular os riscos globais, retardados e irreversíveis. Os riscos globais constituem os riscos em larga escala que podem afetar vastas regiões do planeta. Esses riscos podem ser provocados pela introdução de novas tecnologias que promovem a aceleração do consumo e a globalização dos mercados. Os riscos retardados são aqueles que se desenvolvem lentamente ao longo do tempo, podem levar gerações para se manifestarem e assumirem uma dimensão catastrófica. Os riscos irreversíveis são aptos a gerarem efeitos irreparáveis para a humanidade. A irreversibilidade conduz a uma característica única: a perda de oportunidades para as futuras gerações $^{86}$.

Ao avaliarem-se esses riscos, conclui-se que as nanotecnologias são aptas a abranger os três tipos de riscos: a) globais, em virtude do rápido desenvolvimento dessa emergente tecnologia, que movimenta anualmente uma indústria bilionária; b) retardados, pois a nanopartículas podem se deslocar facilmente pelo ar, água e solo alcançando diferentes tipos de ecossistema, por exemplo, os nanomateriais deslocam-se rapidamente no meio aquático e no

${ }^{83}$ Wilson Engelmann, Tatiana de Almeida F. R. Cardoso, Os novos poderes e a necessidade de uma regulaçãomundial para as nanotecnologias, "RECHTD”, 2(2010), pág. 81.

${ }^{84}$ Matheus P. Paschoalino, Glauciene P. S. Marcone, Wilson F. Jardim, Os nanomateriais e a questão ambiental, "Química Nova”, 2 v.33 (2010), pág.421.

${ }^{85}$ Maria Alexandra de Sousa Aragão, O principio do nível elevado de proteção e a renovação ecológica dodireito ambiental e dos resíduos, Almedina, Coimbra, 2006, pág. 20.

${ }^{86}$ Alexandra de Sousa Aragão, Princípio da precaução: manual de instruções, " CEDOUA", (2008) pág. 24-25: traz alguns exemplos de riscos globais, irreversíveis e retardados: 1) Os CFC, clorofluorcarbono, gás usado em larga escala desde a década de 50, como solvente orgânico, como refrigerante e como propulsor, em extintores de incêndios e aerossóis; 2) OS OGM organismos geneticamente modificados, pois a libertação no ambiente de OGMs, pela utilização agrícola de variedades vegetais geneticamente modificadas, comporta riscos de poluição genética; 3) Os GEE fenômeno dos gases, com efeito, estufa; entre vários outros exemplos elencados pela autora. 
solo $^{87}$; c) irreversíveis, diante da ausência de estudos científicos que possam garantir a segurança do uso e descarte de nanopartículas no meio ambiente.

O segundo pressuposto para aplicação do princípio da precaução é a incerteza científica. As pesquisas sobre as nanotecnologias são incipientes, e algumas delas vêm mostrando que essa emergente ciência pode causar danos à saúde humana e ao meio ambiente ${ }^{88}$. Se, por um lado, são animadores as perspectivas da nanotecnologia, por outro, não se deve subestimar o potencial de danos para o meio ambiente:

De modo geral, sabe-se muito pouco ou nada sobre a biodisponibilidade, biodegrabilidade e toxidade de novos materiais. A contaminação do meio ambiente por nanomateriais com grande área superficial, boa resistência mecânica e atividade catalítica pode resultar na concentração de compostos tóxicos na superfície de nanoparticulas, com posterior transporte no meio ambiente ou acumulo ao longo de cadeia alimentar; na adsorção de biomolécula, com consequente interferência em processos biológicos in vivo; numa maior resistência à degradação (portanto, maior persistência ao meio ambiente) e em catálise de reações químicas indesejáveis no meio ambiente ${ }^{89}$.

Em outras palavras, o princípio da precaução deve ser aplicado sempre que existir risco em atividades que possam causar danos graves e irreversíveis ao meio ambiente; a ausência de certeza absoluta cientifica não pode ser considerada a fim de se adiarem medidas eficazes com a finalidade de preservação ambiental. "O princípio da precaução aparece para tentar evitar ou diminuir os males da sociedade de risco" $"$.

No caso das nanotecnologias, é importante determinar quais são os riscos que estão sujeitos o ser humano e o meio ambiente, a fim de ponderar quais medidas deverão ser adotadas pelo Estado e pela sociedade, pois, "ainda não há um paradigma geral aplicável para identificação do perigo de nanomateriais, uma abordagem caso a caso para a avaliação dos riscos é necessária"91.

\footnotetext{
${ }^{87}$ N. MUSEE, Nanowastes and the environment: potencial new waste management paradigm. "Elsevier Environment International” 37(2011), pág. 112.

88 André Stringhi Flores, Direito ambiental, mínimo essencial ecológico e as nanotecnologias. $O$ cuidado com uma (nova) perspectiva hermenêutica á tecnologia em escala manométrica, "RDA", 72 (2013), págs. 359-379.

${ }^{89}$ Frank Quina, Nanotecnologia e o meio ambiente: perspectivas e riscos, "Química Nova”, 6 v.27 (2004). Disponível em: <http://www.scielo.br/scielo.php?pid=S0100-40422004000600031\&script=sci arttext>. Acesso em: 22 jul. 2014, p.2.

${ }^{90}$ Teresa Ancona Lopez, Princípio da precaução e evolução da responsabilidade civil, São Paulo, Quartier Latin, 2010, pág. 98.

${ }^{91}$ Do ponto de vista de avaliação de risco as propriedades mais relevantes de um nanomaterial são: tamanho e distribuição de tamanho de partículas (livres), fibras, tubos e bastonetes, que podem ser produzidos durante a manufatura, uso, descarte ou reciclagem do produto; área de superfície específica; estabilidade em diferentes meios (incluindo a habilidade de agregar e desagregar), propriedades de adsorção da superfície; solubilidade em água; reatividade química, fotoativação e potencialidade em gerar espécies reativas de oxigênio. Agência Brasileira de Desenvolvimento Industrial, Nanotecnologia na área da saúde: mercado, segurança e regulação, Rio de Janeiro, 2013, pág. 33.
} 
O papel do Estado, nesse caso, estaria na criação e fiscalização de mecanismos eficazes a fim de controlar a gestão dos riscos da introdução da nanotecnologia na saúde e meio ambiente. Um desses mecanismos ocorre por meio de criação de normas jurídicas que regulem todo o ciclo de vida92dos nanomateriais (produção, consumo, descarte e tratamento dos nanowastes).

Conforme abordado anteriormente, no Brasil, não existem normas específicas que regulem essa emergente tecnologia, o que existe é um conjunto de normas jurídicas reflexas que poderiam ser aplicadas no caso de ocorrência de um dano ao consumidor, trabalhador e ao meio ambiente. A necessidade de regulação das nanotecnologias é desejável "para não limitar o estudo e cercear o desenvolvimento tecnológico, mas para garantir que essas novas nanopartículas sejam utilizadas em prol do ser humano"92. Além das normas que garantiriam um referencial para o uso e descarte dos nanomateriais e permitiriam uma maior segurança jurídica àqueles que investissem no setor, é necessária a participação de todos os setores da sociedade afetados para que as normas de fato possam servir a seu propósito. A responsabilidade deve ser compartilhada, principalmente quando se trabalha com uma tecnologia cujos efeitos são ainda desconhecidos ${ }^{93}$.

Dessa forma, advertem Philippe Kourilsky e Geneviève Viney:

\begin{abstract}
O princípio de precaução (...) impõe especialmente aos poderes públicos, que devem fazer prevalecer os imperativos de saúde e de segurança sobre a liberdade de comércio entre os particulares e entre os Estados. Ele exige que se adotem todas as disposições que permitam, por um custo econômico e socialmente suportável, detectar e avaliar o risco reduzi-lo a um nível aceitável e, se possível, eliminá-lo, informar as pessoas interessadas e recolher suas sugestões sobre as medidas imaginadas para tratá-lo. Esse dispositivo de precaução deve ser proporcional à amplitude do risco e pode ser a todo o momento revisto ${ }^{94}$.
\end{abstract}

Entre os princípios previstos no artigo 225 da CF/88, destacam-se o princípio da informação $0^{95}$ e participação em prol da conscientização pública. O principio da informação atua aqui como mais um instrumento em favor da

92 Wilson Engelmann, Airton Guilherme Berger Filho, As nanotecnologias e o direito ambiental: a mediação entre custos e beneficios na construção de marcos regulatórios, "RDA", 59 (2010), pág. 187.

${ }_{93}$ De acordo com Ayala e Leite “(...) esta tarefa de atuar, preventivamente, deve ser vista como uma responsabilidade compartilhada, exigindo uma atuação de todos os setores da sociedade, cabendo ao Estado criar instrumentos normativos e política preventiva". Patryck de Araújo Ayala, José Rubens Morato Leite, Danoambiental do individual ao coletivo extrapatrimonial. Teoria e prática, São Paulo, Revista dos Tribunais, 2012, pág.67.

${ }^{4}$ Philippe Kourilky, Geneviève Viney, Le príncipe de précaution: rapport au premier ministre, Revista deDireito Sanitário, 1 v.2(2001), pág. 150.

${ }^{95} \mathrm{O}$ direito á informação pode ser comtemplado em três aspectos distintos: a) o direito de informar (artigo 220, caput, combinado com o artigo $5^{\circ}$, inciso IX, CF/88; b) o direito de se informar (artigo $5^{\circ}, \mathrm{XIV}$; c) o direito deser informado (artigo $5^{\circ}$, inciso XXXIII, combinado com o artigo 37, caput da CF/88. Rizzato Nunes, Curso deDireito do consumidor, São Paulo, Saraiva, 2012, pág. 97. 
eficiência do sistema regulatório ${ }^{96}$. No caso das nanotecnologias é importante que os consumidores sejam informados dos potenciais riscos dessa tecnologia e possam avaliar com segurança sobre a possibilidade de consumo dos nanoprodutos, outra questão deveria ser objeto de informação aos setores sociais é o descarte adequado dos nanowastes, de forma a possibilitar o seu gerenciamento.

Sobre a participação dos cidadãos na questão ambiental, o princípio $10 \mathrm{da}$ Declaração do Rio de Janeiro de 1992 prevê:

A melhor maneira de tratar as questões ambientais é assegurar a participação, no nível apropriado, de todos os cidadãos interessados. No nível nacional, cada indivíduo terá acesso adequado às informações relativas ao meio ambiente de que disponham as autoridades públicas, inclusive informações acerca de materiais e atividades perigosas em suas comunidades, bem como a oportunidade de participar dos processos decisórios. Os Estados irão facilitar e estimular a conscientização e a participação popular, colocando as informações à disposição de todos. Será proporcionado o acesso efetivo a mecanismos judiciais e administrativos, inclusive no que se refere à compensação e reparação de danos.

Conclui-se que o princípio da precaução constitui um mecanismo essencial, no gerenciamento dos riscos das nanotecnologias, o que não significa a estagnação do progresso científico, "mas é justamente o contrário, pois uma das preocupações subjacentes ao princípio da precaução é, preferencialmente, a de permitir a introdução da ciência no âmbito da decisão na esfera pública" ${ }^{\prime 97}$. A avaliação, investigação e gestão dos riscos produzidos por essa ciência deverá abranger todo o seu ciclo de vida, pesquisa, desenvolvimento, produção, consumo, descarte e tratamento de resíduos, e não pode ser ignorado quando existe a necessidade de uma ação urgente diante de um perigo potencial para a saúde humana, de plantas e animais mesmo nos casos em que os dados científicos não permitam uma avaliação precisa desses riscos.

\section{Considerações finais}

Como se sabe, os riscos são inerentes às atividades desenvolvidas pelo homem, no entanto, as novas descobertas tecnológicas podem produzir resultados incertos e, diante da possibilidade da ocorrência de ameaças à saúde dos homens e do meio ambiente, é desejável o conhecimento e o gerenciamento dos riscos que as nanotecnologias podem ocasionar. Uma vez que a inteligência humana é

96 Patrícia Faga Iglecias Lemos, Resíduos sólidos e responsabilidade civil pós-consumo, São Paulo, Revista dos Tribunais, 2012, pág.54.

${ }^{97}$ Cristine Noiville, Ciência decisão e ação: três observações em torno do principio da precaução, Governodos riscos, 2005, pág. 47 .Disponível em: $<$ http://www.marcelodvarella.org/Riscos_files/ Governo\%20dos\%20Riscos.pdf $>$. Acesso em: 07 de out. 2014. 
ilimitável, o progresso científico tende a ampliar os conhecimentos do homem em relação ao seu ambiente natural, entretanto "a ciência pode, do mesmo modo, aumentar a lacuna entre o que se sabe e o que se gostaria de saber"98.

A nanotecnologia como um conjunto de técnicas utilizadas a fim de manipular a matéria na escala de átomos e moléculas está carente de regulamentação em diversos países, inclusive no Brasil, pouco se sabe sobre os riscos advindos do consumo dessa emergente tecnologia.

Dados recentes demonstram que "(...) a produção anual estimada de materiais que contêm substâncias em nanoescala saltou de 1.000 toneladas em 2004 para 5.000 atualmente, com a perspectiva de que a marca de 100.000 toneladas seja atingida na próxima década" ${ }^{99}$. Devido à potência desses nanomateriais, isso poderia ter um impacto ecológico equivalente a 5 milhões de toneladas $3 / 4$ ou talvez até 50 bilhões de toneladas $3 / 4$ de materiais convencionais ${ }^{100}$. Esses dados corroboram o inevitável aumento do consumo e do descarte de nanoprodutos, além de, consequentemente, surgimento de novos problemas ambientais tais como a possibilidade de risco de contaminação do ar, da água e do solo, pois, até aonde se tem conhecimento, é o tamanho diminuto das nanopartículas que facilita difusão e o transporte na atmosfera, água e solo.

Diante da incerteza científica sobre os potenciais riscos que os nanomateriais podem causar à saúde humana e ao meio ambiente, e da ausência regulamentação específica sobre o tema, recomenda-se a aplicação do princípio da precaução, como instrumento hábil a possibilitar o gerenciamento de todo o ciclo de vida dos nanomateriais (produção, consumo, descarte e tratamento dos nanowastes).

\footnotetext{
98 Mary Douglas, Aaron Wildavsky,Risco e cultura Um ensaio sobre a seleção de riscos tecnológicos e ambientais, Rio de Janeiro, Elsevier, 2012, pág. 3.

${ }^{99}$ Matheus PPaschoalino, Glauciene P. S.Marcone, Wilson FJardim, Os nanomateriais e a questão ambiental,“Química Nova”, 2 v.33 (2010), pág.421.

${ }^{100}$ Projeto de Lei 6741/2013.
} 


\section{Referências}

A. D. Maynard, Nanotechnology: A Research strategy for addressing risk, Woodrow Wilson International Center for Scholars, 2006.

Agência Brasileira de Desenvolvimento Industrial (ABDI), Panorama da nanotecnologia no mundo eno Brasil, 2010. Disponível em: $<\mathrm{http}$ ://www. desenvolvimento.gov.br/arquivos/dwnl_1266607883.pdf>. Acesso em: 22 jul. 2014.

Agencia Brasileira de Desenvolvimento Industrial (ABDI), Cartilha sobre nanotecnologia, Brasília, ABDI, 2011.

Agência Brasileira de Desenvolvimento Industrial (ABDI),Nanotecnologia na área da saúde: mercado, segurança e regulação, Rio de Janeiro, 2013. Disponível em: < http://www3.eco.unicamp.br/neit/images/stories/ Setoriais_fase_II/relatorio-nanotecnologia.pdf>. Acesso em: 7 out. 2014. André Stringhi Flores, Direito ambiental, mínimo essencial ecológico e as nanotecnologias. O cuidado com uma (nova) perspectiva hermenêtica á tecnologia em escala manométrica,"RDA", 72 (2013), págs. 359-379.

Beatriz Souza Costa, José Cláudio Junqueira Ribeiro, Gestão e gerenciamento de resíduos sólidosDireitos edeveres, Lumen Juris, Rio de Janeiro, 2013.

Bystrzejewska-Piotrowska, Nanoparticles: their potential toxicity, waste and environmentalmanagement, Waste Management, "Elsevier Ltd." 9, v. 29 (2009), págs.2587-2595. Disponível em: <http://www.ncbi.nlm.nih.gov/ pubmed/19427190>. Acesso em: 22 jul.2014.

Carlos Felipe Mendoza, Laura Meraz Cabrera, Hacia la nanociencia verde nanomateriales, nanoproductos ynanorresiduos, UNAM- Universidade do México, "Materiales Avanzados", 19 (2012), págs. 39-42.

Cristine Noiville, Ciência decisão e ação três observações em torno do principio da precaução,Governodos riscos, 2005, pág. 47 .Disponível em: $<$ http://www.marcelodvarella.org/Riscos_files/Governo $\% 20 \mathrm{dos} \% 20$ Riscos.pdf $>$. Acesso em: 07 de out. 2014

Eric Drexler, Engines of criation- The coming era of nanotechnology, 1986.

Frank Quina, Nanotecnologia e o meio ambiente: perspectivas e riscos, "Química Nova", 6 v.27 (2004), pág 2. Disponível em: <http://www.scielo. br/scielo.php?pid=S0100-40422004000600031\&script=sci_arttext $>$. Acesso em: 22 jul. 2014.

Gerd Winter, A natureza jurídica dos princípios ambientais em direito internacional, direito da Comunidade Europeia e direito nacional, [em, Sandra Akemi Shimada Kishi, Solange Teles Silva, Ines Virginia Prado Sores,coord.: Desafios do direito ambiental no século XXI: Estudos em homenagem a Paulo Affonso Leme Machado. São Paulo, Malheiros, 2005], pág. 144. 
Helena Pereira de Melo, A aplicação do princípio da precaução á nanotecnologia, "FDUP Faculdade de Direito da Universidade do Porto", 7 (2010), págs. 343-381.

HenriquetaLouro, TeresaBorges, Maria JoãoSilva, Nanomateriais manufaturados novos desafios para asaúde pública,"Portuguesa de Saúde Pública", 22 (2013),pág. 13.

José JailtonDamasceno, Ana R.Ribeiro, Luciene BBalottin, José MauroGranjeiro,Nanometrologia-desafios para a regulação sanitária,"Vi gilânciaSanitária",1(4)(2013).

Juliana Vieira Santos, A gestão dos resíduos sólidos urbanos: um desafio. Tese (doutorado), Faculdade de Direito do Largo São Francisco da USP, São Paulo, 2009.

Lei 11.105 de 24 de março de 2005, Brasil,Regulamenta os incisos II, IV e V do $\S 1$ o do art. 225 da Constituição Federal, estabelece normas de segurança e mecanismos de fiscalização de atividades que envolvam organismos geneticamente modificados - OGM e seus derivados e dá outras providências. Disponível em: $<$ http://www.planalto.gov.br/ ccivil_03/leis/ 18078. htm>.Acesso em: 28 jul. 2014.

Liziane Paixão Silva Oliveira,A Convenção sobre Diversidade Biológica $e$ $o$ princípio da soberania, Dissertação de Mestrado, Universidade de Brasília, Pós-Graduação em Direito, 2006. Disponível em: <http://bdtd. bce.unb.br/tedesimplificado/tde busca/arquivo.php?codA rquivo $=4379>$. Acesso em: 27 jun. 2014.

Maria Alexandra de Sousa Aragão,Direito dos resíduos sólidos, CadernosCEDOUA, Coimbra, 2000. Maria Alexandra de Sousa Aragão, $O$ princípio do nível elevado de proteção e a renovação ecológica do direito ambiental e dos resíduos, Almedina, Coimbra, 2006.

Maria Alexandra de Sousa Aragão, Princípio da precaução manual de instruções, "CEDOUA", (2008).

Mary Douglas, Aaron Wildavsky, Risco e cultura Um ensaio sobre a seleção de riscos tecnológicos e ambientais, Rio de Janeiro, Elsevier, 2012.

Matheus PPaschoalino, Glauciene P. S.Marcone, Wilson FJardim,Os nanomateriais e a questão ambiental,“Química Nova”, 2 v.33 (2010), págs.421-430.

Ministério da Ciência e Tecnologia e Inovação (MCTI), Brasil,Governo vai investir R\$ 440 milhõesem nanotecnologia. Disponível em: <www.ebc. com.br/tecnologia/20 13/.../governo-vai-investir-r-440-milhoes. >. Acesso em: 22 jul. 2014.

N. MUSEE, Nanowastes and the environment: potencial new waste management paradigm, "Elsevier Environment International" 37(2011), págs. 111-128. 
Niklas Luhmann, Risk: a sociology theory, New Jersey, Translation Publishers, 2008.

Patrícia Faga Iglecias Lemos, Resíduos sólidos e responsabilidade civil pósconsumo, São Paulo, Revista dos Tribunais, 2012.

Patrícia F. M. Nogueira, Iêda Maria M.Paino, Valtencir Zucolotto, Nanosilver: Propriedades, aplicações e impactos na saúde pública e meio ambiente, "Vigilância Sanitária em Debate", 1(4) (2013), págs. 59-71.

Patryck de Araújo Ayala, José Rubens Morato Leite, Danoambiental do individual ao coletivo extrapatrimonial. Teoria e prática, São Paulo, Revista dos Tribunais, 2012, pág.67.

Paulo Martins, Nanotecnologia e meio ambiente para uma sociedade sustentável, "Estudios sociales", 17 ( 2009), no 34, México.

Philippe Kourilky, Geneviève Viney, Le príncipe de précaution: rapport au premier ministre, Revista deDireito Sanitário, 1 v.2(2001), pág. 150.

Rafael Luiz Ferronato,Nanotecnologia, ambiente e direito: desafios para a sociedade na direção a um marcoregulatório, 2010 (111 fls.) Tese (Mestrado em Direito) Universidade Caxias do Sul, Caxias do Sul (RS), 2010.

Rizzato Nunes, Curso de Direito do consumidor, São Paulo,Saraiva, 2012.

Teresa Ancona Lopez, Princípio da precaução e evolução da responsabilidade civil, São Paulo, Quartier Latin, 2010.

Ulrich Beck, Sociedade de Risco: rumo a uma outra modernidade,São Paulo, Editora 34, 2010.

Wilson Engelmann, Airton Guilherme Berger Filho, As nanotecnologias e o direito ambiental: a mediação entre custos e benefícios na construção de marcos regulatórios, "RDA", 59 (2010), págs. 50- 91.

Wilson Engelmann, Tatiana de Almeida F. R. Cardoso, Os novos poderes e a necessidade de uma regulaçãomundial para as nanotecnologias, "RECHTD”, 2(2010), págs 175-192. 
